\title{
Effect of the Synthesis Method on the Phase Composition and Magnetism of Layered Double Hydroxides
}

\author{
O. V. Nestroinia ${ }^{a}$, I. G. Ryl’tsova ${ }^{a}$, M. N. Yapryntsev ${ }^{a}$, and O. E. Lebedeva ${ }^{a}$ * \\ ${ }^{a}$ Belgorod National Research University, ul. Pobedy 85, Belgorod, 308015 Russia \\ *e-mail: OLebedeva@bsu.edu.ru \\ Received August 26, 2019; revised December 19, 2019; accepted January 23, 2020
}

\begin{abstract}
A number of tetrametallic layered double hydroxides containing magnesium and cobalt on the site of doubly charged cations in the structure of brucite-like layers and aluminum and iron on the site of triply charged cations have been synthesized using three distinct methods: coprecipitation, microwave synthesis, and hydrothermal crystallization. A sodium hydroxide solution was used as a precipitant. The results demonstrate that all three methods yield a well-crystallized hydrotalcite-like layered hydroxide and an impurity phase. We believe that it is the impurity phase which is responsible for the magnetism of the materials. Most likely, this phase is spinel $\mathrm{CoFe}_{2} \mathrm{O}_{4}$.
\end{abstract}

Keywords: layered double hydroxides, cobalt, iron, magnetic properties, spinel phase

DOI: $10.1134 / \mathrm{S} 0020168520070109$

\section{INTRODUCTION}

The layered double hydroxides (LDHs), or hydrotalcite-like compounds, are basic salts with an unusual layered structure. The general formula of this class of compounds is $\left[\mathrm{M}_{1-x}^{2+} \mathrm{M}_{x}^{3+}(\mathrm{OH})_{2}\right]^{x+}\left[\left(\mathrm{A}^{n-}\right)_{x / n} \cdot m \mathrm{H}_{2} \mathrm{O}\right]$, where $\mathrm{M}^{2+}$ and $\mathrm{M}^{3+}$ are metal ions residing on the octahedral site in the brucite-like layers and $\mathrm{A}^{n-}$ represents anions, which compensate for the positive charge of the brucite-like layers [1, 2]. The specific structural features of the hydrotalcite-like compounds and the diversity of cations that can be present in their composition underlie the unique ion-exchange [3], sorption $[4,5]$, electrical [6], and catalytic [7, 8] properties of the LDHs and their thermal destruction products. Considerable attention has been attracted by the possibility of preparing LDHs having magnetic properties. Such an effect is observed if both iron and cobalt cations are present in the system [9].

In a previous study, Ryl'tsova et al. [10] synthesized a $\mathrm{MgCo} / \mathrm{AlFe} \mathrm{LDH}$ series in carbonate form via coprecipitation at variable $\mathrm{pH}$. It was shown that only iron- and cobalt-rich samples had magnetic properties, which was most likely due to the presence of an impurity phase. Those materials, which were in effect, composites, were proposed for use as magnetic sorbents [11].

The necessity of adding large amounts of iron and cobalt to obtain magnetic materials has a negative effect on the crystallinity of the hydrotalcite-like phase.
The purpose of this research was to find a method and optimize conditions for the synthesis of $\mathrm{MgCo} / \mathrm{AlFe} \mathrm{LDH}$ materials having magnetic properties at room temperature at the minimum possible iron and cobalt concentrations.

\section{EXPERIMENTAL}

As sources of metal cations, we used the following salts: $\mathrm{Mg}\left(\mathrm{NO}_{3}\right)_{2} \cdot 6 \mathrm{H}_{2} \mathrm{O}, \mathrm{Co}\left(\mathrm{NO}_{3}\right)_{2} \cdot 6 \mathrm{H}_{2} \mathrm{O}, \mathrm{Al}\left(\mathrm{NO}_{3}\right)_{3}$. $9\left(\mathrm{H}_{2} \mathrm{O}\right)$, and $\mathrm{Fe}\left(\mathrm{NO}_{3}\right)_{3} \cdot 9 \mathrm{H}_{2} \mathrm{O}$. All of the reagents were of analytical grade.

Multimetallic LDHs with the general formula $\left(\mathrm{Mg}_{1-x} \mathrm{Co}_{x}\right)_{6}\left(\mathrm{Al}_{1-y} \mathrm{Fe}_{y}\right)_{2} \mathrm{NO}_{3} \cdot m \mathrm{H}_{2} \mathrm{O}$ were synthesized by three methods: coprecipitation at variable $\mathrm{pH}$, hydrothermal crystallization, and microwave processing. The degree of substitution of cobalt for magnesium $(x)$ and iron for aluminum $(y)$ was varied in the range $10-50$ at $\%$.

Coprecipitation was carried out by adding a sodium hydroxide solution to a solution containing appropriate amounts of salts. The total concentration of metal ions in the starting reaction mixture was $1 \mathrm{M}$, and the ratio of the molar concentration of the doubly charged ions to that of the triply charged ions was $\left[\mathrm{M}^{2+}\right] /\left[\mathrm{M}^{3+}\right]=3$. During the synthesis process, the $\mathrm{pH}$ of the mixture was brought to $9-10$. The resultant precipitates were aged under the mother liquor for $24 \mathrm{~h}$ at room temperature and for an additional two days at $98^{\circ} \mathrm{C}$. The hydrothermal synthesis of the LDHs was carried out in an Autoclave Engineers Parker autoclave at a temperature of $140^{\circ} \mathrm{C}$ and a pressure in the range $250-304 \mathrm{kPa}$ over a 
period of two days. In microwave synthesis, we used a 700-W MARS-6 reactor. The microwave treatment time was $10 \mathrm{~min}$. In the hydrothermal and microwave syntheses, the composition and $\mathrm{pH}$ of the reaction mixture were identical to those indicated above for the coprecipitation method. Hereafter, the following designations are used for the samples prepared via coprecipitation, hydrothermal crystallization, and microwave synthesis: $\mathrm{MgCo} X / \mathrm{AlFe} Y$-c, $\operatorname{MgCo} X / \mathrm{AlFe} Y$-ht and $\mathrm{MgCo} X / \mathrm{AlFe} Y$-mw, respectively, where $X$ and $Y$ are the nominal mole percentages of cobalt and iron among the di- and trivalent metals in the starting mixture. The precipitation products obtained by all three methods were separated from the mother liquor, and the samples were washed with distilled water and dried at $120^{\circ} \mathrm{C}$.

$\mathrm{X}$-ray diffraction patterns were collected on a Rigaku diffractometer ( $\mathrm{Cu} K_{\alpha}$ radiation) with a $2 \theta$ scan step of $0.02^{\circ}$. The morphology of the synthesized LDHs was examined by transmission electron microscopy (TEM) on a JEOL JEM-2100 operated at an accelerating voltage of $200 \mathrm{kV}$. In addition, the structure of the samples was characterized by selected area electron diffraction. The elemental composition of the samples was determined on a FEI Quanta 200 3D scanning electron microscope equipped with an EDAX energy dispersive X-ray (EDX) spectrometer system, at an accelerating voltage of $30 \mathrm{kV}$. IR spectra of the synthesized materials were measured on a Shimadzu IR Prestige 21 Fourier transform IR spectrometer using samples pressed with potassium bromide. The ability of the samples to be attracted by a magnet was assessed using a magnet in the form of a parallelepiped $49 \times 8 \times 4 \mathrm{~mm}$ in dimensions, made of a $\mathrm{Nd}-\mathrm{Fe}-\mathrm{B}$ alloy.

\section{RESULTS AND DISCUSSION}

In a previous study [10], a mixture of sodium hydroxide and sodium carbonate was used as a precipitant solution in the synthesis of iron- and cobalt-containing LDHs in carbonate form. As shown in subsequent experiments, precipitation with only a sodium hydroxide solution leads to manifestation of magnetic properties at considerably smaller amounts of iron and cobalt in the samples. In this study, sodium hydroxide was used as a precipitant. As a result, nitrate anions prevailed in the LDH samples, but the presence of carbonates originating from atmospheric carbon dioxide was also possible.

The presence of nitrogen in the samples was confirmed by X-ray microanalysis results (Fig. 1). Carbon content (in the form of carbonates) was below the detection limit of the method. The EDX spectra detected all of the metals used in synthesis, without signals from foreign elements. Table 1 presents the atomic fractions of the metal cations as evaluated from the X-ray microanalysis results. It follows from the
$\mathrm{M}^{2+} / \mathrm{M}^{3+}$ ratio that the content of doubly charged cations in the samples prepared via coprecipitation is on average higher than that in the samples prepared by the other two methods. The content of doubly charged cations is relatively lower in the samples prepared by microwave synthesis.

The IR spectra of all the samples are typical of the hydrotalcite-like compounds (Fig. 2) and confirm the presence of nitrate anions in the composition of the synthesized materials. The spectra contain a split band in the range $1370-1515 \mathrm{~cm}^{-1}$. The strong peak at $1384 \mathrm{~cm}^{-1}$ is commonly assigned to antisymmetric stretching vibrations of nitrate anions. The shoulder between 1470 and $1515 \mathrm{~cm}^{-1}$ is attributable to a reduction in the symmetry of some nitrate anions from $D_{3 \mathrm{~h}}$ to $C_{2 \mathrm{v}}$, that is, from "free" anions to monodentate and/or bidentate ones [12]. According to data in the literature, the region under $1000 \mathrm{~cm}^{-1}$ contains not only bands corresponding to bending vibrations of nitrate anions but also bands arising from metal-oxygen vibrations [12-14]. The weak band in the range 2250-2375 $\mathrm{cm}^{-1}$ is commonly assigned to atmospheric $\mathrm{CO}_{2}$.

Figures 3-5 show X-ray diffraction patterns of the samples prepared by different techniques. In all cases, the LDH phase prevails: all the X-ray diffraction patterns contain seven reflections from it: 003, 006, $009 / 012,015,018,110$, and 113 . The strongest and narrowest reflections are observed in the $\mathrm{X}$-ray diffraction patterns of the LDH samples synthesized under hydrothermal conditions (Fig. 4), suggesting that these samples have a high degree of crystallinity. Using the Rietveld method, we evaluated the lattice parameters of the LDHs (Table 1). The $c$ cell parameter correlates with the interlayer spacing, and the $a$ cell parameter characterizes the distance between neighboring cations in the brucite-like layers $[1,15,16]$. The incorporation of cobalt and iron cations, which are larger than magnesium and aluminum, into the structure of the brucite-like layers was expected to cause an increase in the parameter $a$. Indeed, there is such a trend in the LDH series prepared through coprecipitation and by hydrothermal treatment (Table 1): $a$ increases with increasing iron and cobalt content.

All of the synthesized samples, except $\mathrm{MgCo} 10 / \mathrm{AlFe} 10-\mathrm{mw}$, readily become agglomerated under the effect of an external magnetic field and are capable of attracting to a magnet. There are two opposite opinions in the literature as to the nature of the ferromagnetism of cobalt-iron LDHs. It was reported by Li et al. [9] that room-temperature ferromagnetism was only observed in samples containing more than 50 at $\%$ cobalt and iron on the sites of doubly and triply charged cations, respectively. They interpreted the ferromagnetism of the obtained LDHs in terms of the coexistence of $\mathrm{Co}^{2+}-\mathrm{O}^{2-}-\mathrm{Co}^{2+}$ ferromagnetic interactions and $\mathrm{Co}^{2+}-\mathrm{O}^{2-}-\mathrm{Fe}^{3+}$ and $\mathrm{Fe}^{3+}-\mathrm{O}^{2-}-\mathrm{Fe}^{3+}$ antiferromagnetic interactions. This inference was, 

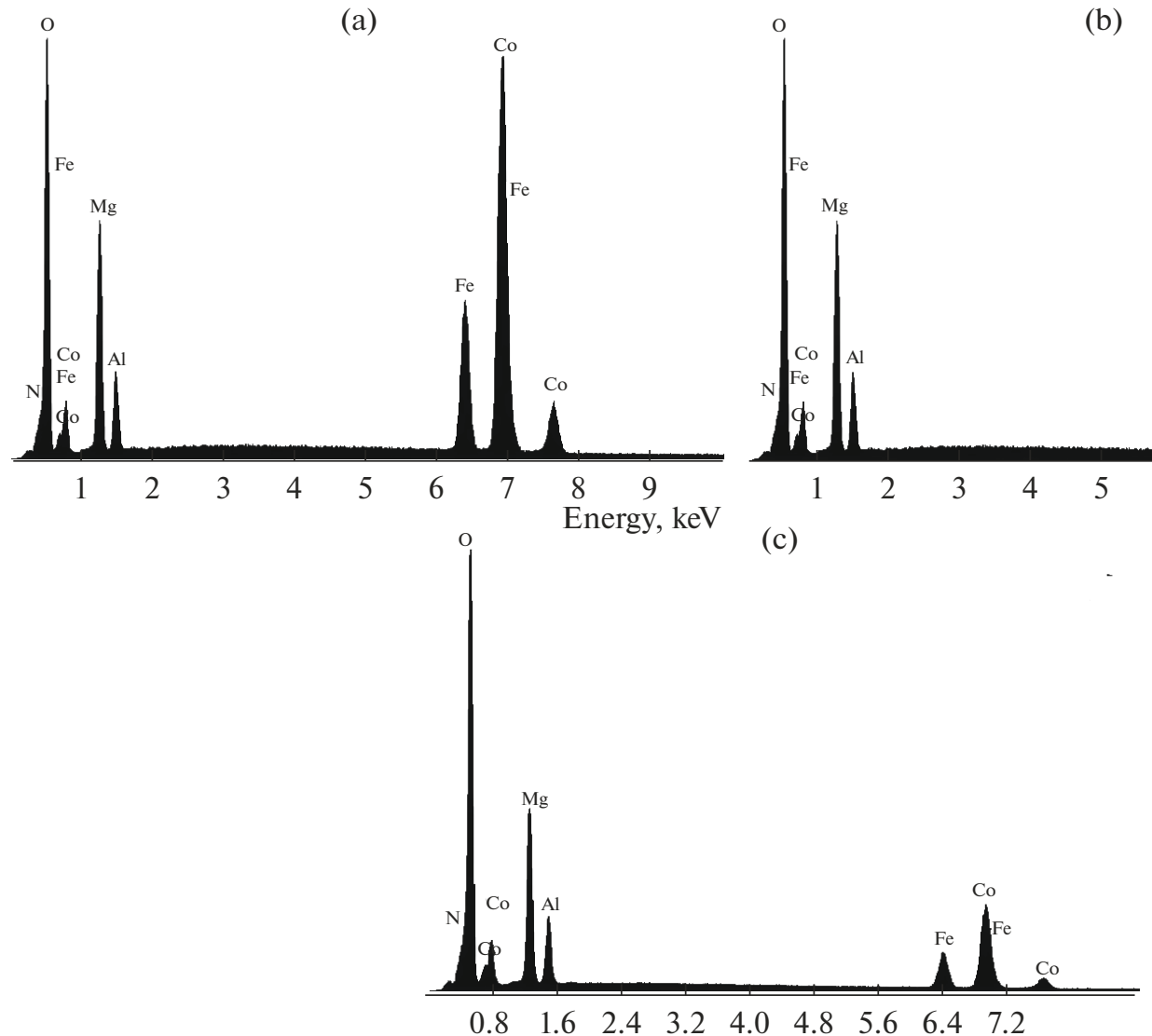

(b)

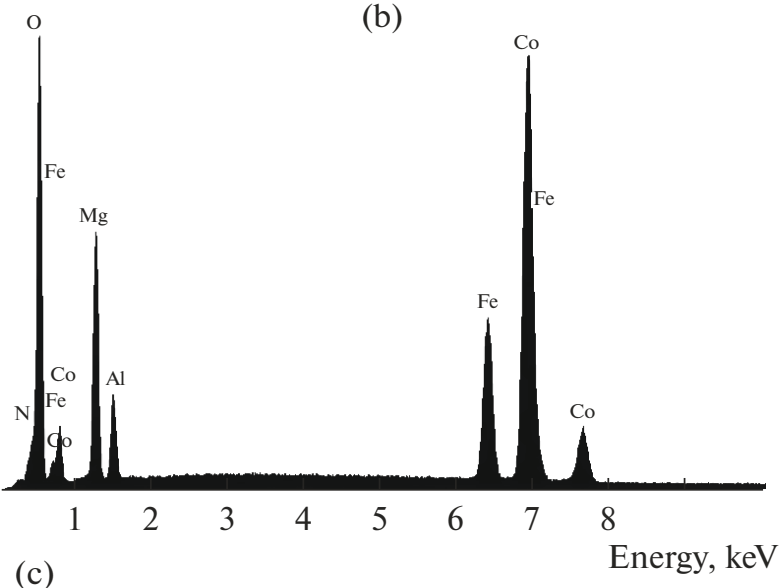

Energy, keV

Fig. 1. Energy dispersive X-ray microanalysis results for the samples prepared by different techniques: (a) MgCo40/AlFe40-c, (b) $\mathrm{MgCo} 40 / \mathrm{AlFe} 40-\mathrm{ht}$, and (c) $\mathrm{MgCo} 40 / \mathrm{AlFe} 40-\mathrm{mw}$.

Table 1. Atomic fractions of the constituent metal cations and lattice parameters of the LDH phase

\begin{tabular}{|c|c|c|c|c|c|c|c|}
\hline \multirow{2}{*}{ Sample } & \multicolumn{4}{|c|}{ Atomic fractions of the cations ${ }^{*}$} & \multirow{2}{*}{$\mathrm{M}^{2+} / \mathrm{M}^{3+}$} & \multirow{2}{*}{$c, \AA$} & \multirow{2}{*}{$a, \AA$} \\
\hline & $\mathrm{Mg}^{2+}$ & $\mathrm{Co}^{2+}$ & $\mathrm{Al}^{3+}$ & $\mathrm{Fe}^{3+}$ & & & \\
\hline $\mathrm{MgCo} 10 / \mathrm{AlFe} 10-\mathrm{c}$ & 0.682 & 0.096 & 0.191 & 0.031 & 3.50 & 23.88 & 3.09 \\
\hline $\mathrm{MgCo} 20 / \mathrm{AlFe} 20-\mathrm{c}$ & 0.604 & 0.173 & 0.172 & 0.052 & 3.48 & 24.14 & 3.09 \\
\hline $\mathrm{MgCo} 30 / \mathrm{AlFe} 30-\mathrm{c}$ & 0.512 & 0.258 & 0.145 & 0.085 & 3.35 & 23.84 & 3.09 \\
\hline $\mathrm{MgCo} 40 / \mathrm{AlFe} 40-\mathrm{c}$ & 0.435 & 0.338 & 0.117 & 0.109 & 3.41 & 24.00 & 3.10 \\
\hline $\mathrm{MgCo} 50 / \mathrm{AlFe} 50-\mathrm{c}$ & 0.382 & 0.388 & 0.101 & 0.128 & 3.36 & 23.93 & 3.12 \\
\hline MgCo10/AlFe10-ht & 0.672 & 0.091 & 0.203 & 0.035 & 3.22 & 23.88 & 3.03 \\
\hline $\mathrm{MgCo} 20 / \mathrm{AlFe} 20-\mathrm{ht}$ & 0.595 & 0.168 & 0.186 & 0.051 & 3.21 & 23.97 & 3.09 \\
\hline $\mathrm{MgCo} 30 / \mathrm{AlFe} 30-\mathrm{ht}$ & 0.524 & 0.225 & 0.172 & 0.079 & 2.97 & 23.93 & 3.09 \\
\hline $\mathrm{MgCo} 40 / \mathrm{AlFe} 40-\mathrm{ht}$ & 0.447 & 0.306 & 0.139 & 0.109 & 3.04 & 24.02 & 3.10 \\
\hline $\mathrm{MgCo} 50 / \mathrm{AlFe} 50-\mathrm{ht}$ & 0.366 & 0.382 & 0.126 & 0.127 & 2.97 & 23.94 & 3.12 \\
\hline $\mathrm{MgCo} 10 / \mathrm{AlFe} 10-\mathrm{mw}$ & 0.633 & 0.102 & 0.228 & 0.037 & 2.78 & 23.30 & 3.07 \\
\hline $\mathrm{MgCo} 20 / \mathrm{AlFe} 20-\mathrm{mw}$ & 0.572 & 0.187 & 0.179 & 0.062 & 3.14 & 24.53 & 3.10 \\
\hline $\mathrm{MgCo} 30 / \mathrm{AlFe} 30-\mathrm{mw}$ & 0.486 & 0.264 & 0.161 & 0.089 & 3.00 & 23.83 & 3.08 \\
\hline $\mathrm{MgCo} 40 / \mathrm{AlFe} 40-\mathrm{mw}$ & 0.449 & 0.295 & 0.147 & 0.108 & 2.92 & 23.49 & 3.10 \\
\hline $\mathrm{MgCo} 50 / \mathrm{AlFe} 50-\mathrm{mw}$ & 0.345 & 0.400 & 0.116 & 0.138 & 2.93 & 23.48 & 3.07 \\
\hline
\end{tabular}

* Evaluated from the EDX spectra. 


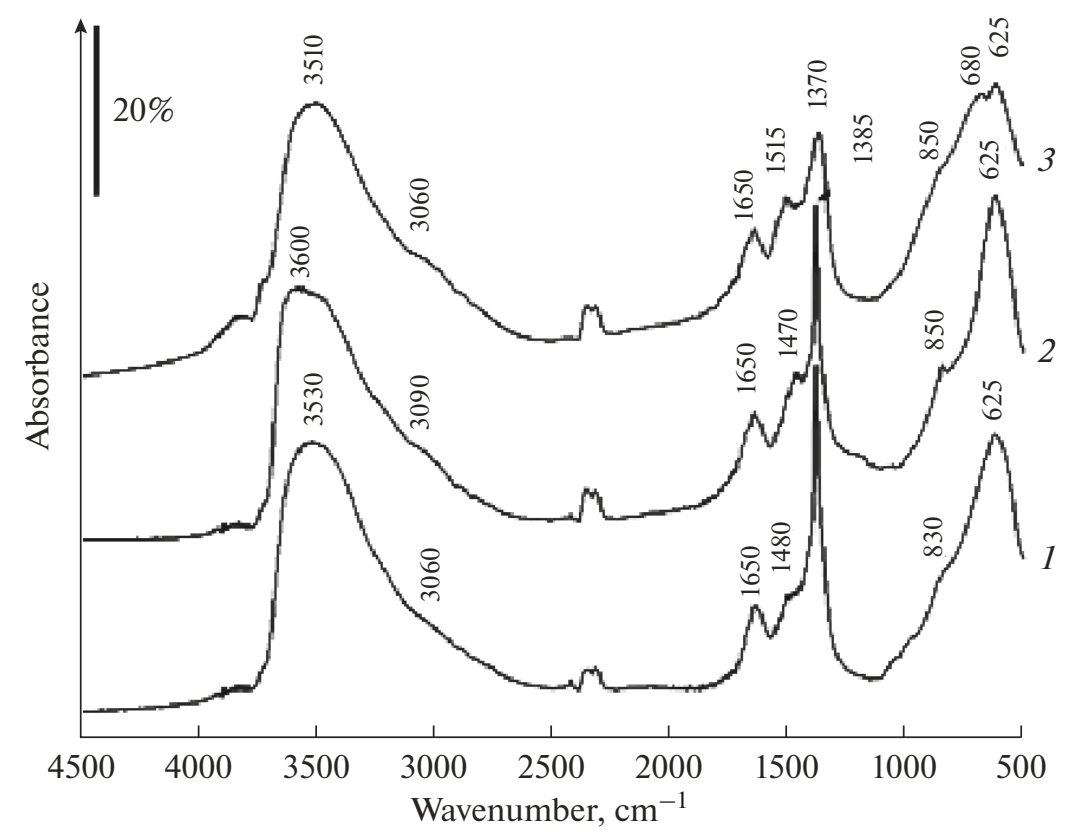

Fig. 2. IR spectra of the samples prepared by different techniques: (1) MgCo40/AlFe40-c, (2) MgCo40/AlFe40-ht, and (3) $\mathrm{MgCo} 40 / \mathrm{AlFe} 40-\mathrm{mw}$.

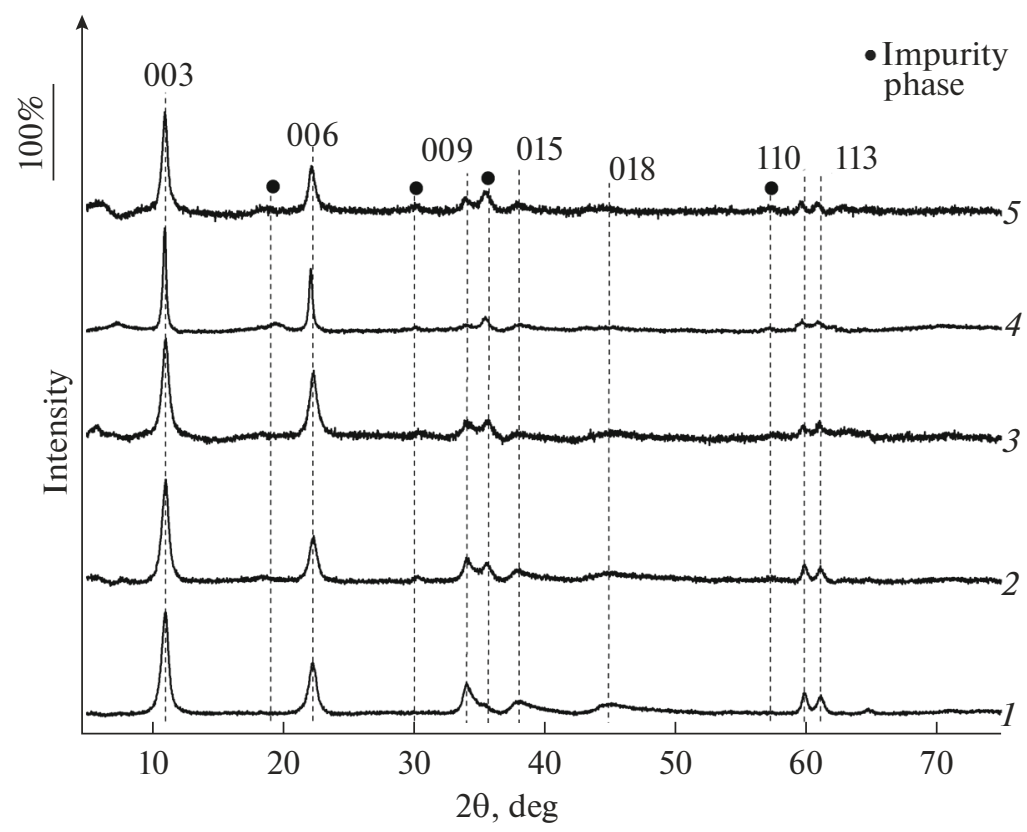

Fig. 3. X-ray powder diffraction patterns of the samples prepared through coprecipitation: (1) $\mathrm{MgCo} 10 / \mathrm{AlFe} 10$, (2) MgCo20/AlFe20, (3) MgCo30/AlFe30, (4) MgCo40/AlFe40, (5) MgCo50/AlFe50.

however, refuted by Abellen et al. [17]. They believe that room-temperature magnetism in such systems can be due to the presence of amorphous impurity phases, such as ferrihydrite $(\mathrm{FeOOH})$ or iron oxide (maghemite and magnetite) nanoparticles, which can be undetected by X-ray diffraction.
The present results are consistent with what was reported by Abellen et al. [17]. Most of the samples synthesized by us are not single-phase materials. Their $\mathrm{X}$-ray diffraction patterns show reflections from an impurity phase, and there are grounds to believe that this phase is responsible for the magnetic properties of 


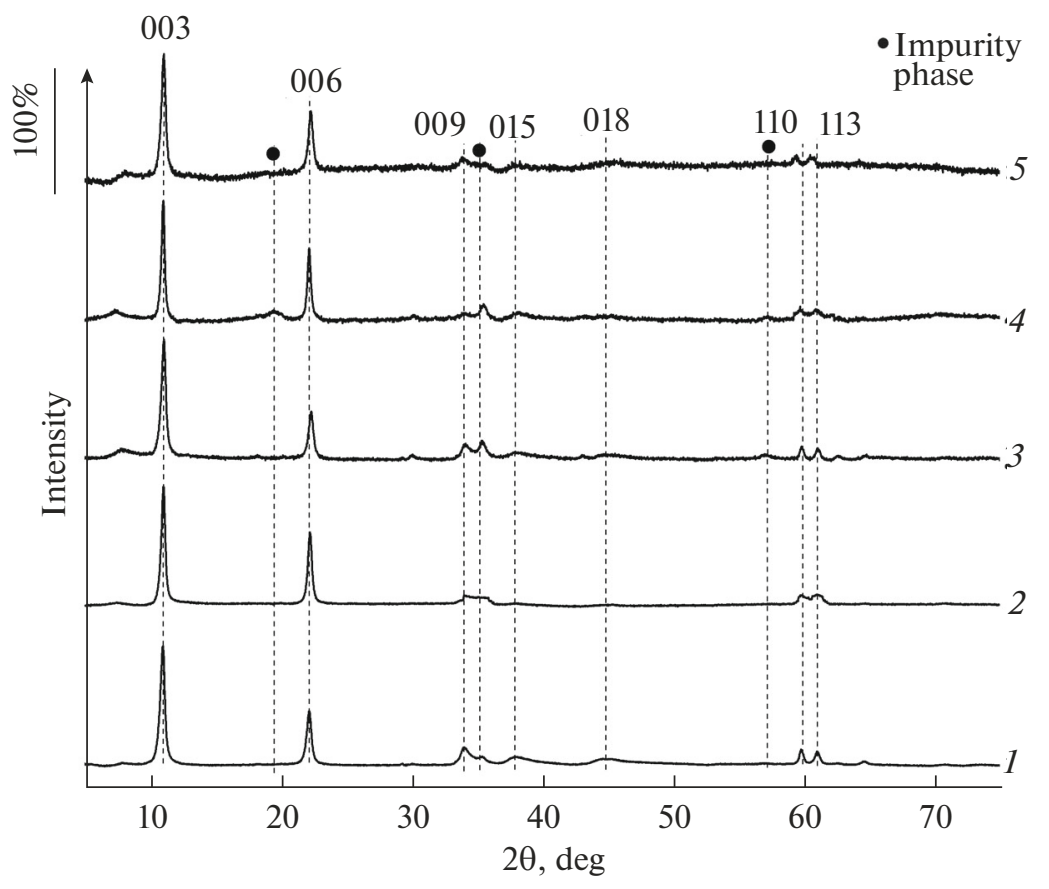

Fig. 4. X-ray powder diffraction patterns of the samples prepared by hydrothermal synthesis: (1) MgCo10/AlFe10, (2) $\mathrm{MgCo} 20 / \mathrm{AlFe} 20$, (3) MgCo30/AlFe30, (4) MgCo40/AlFe40, (5) MgCo50/AlFe50.

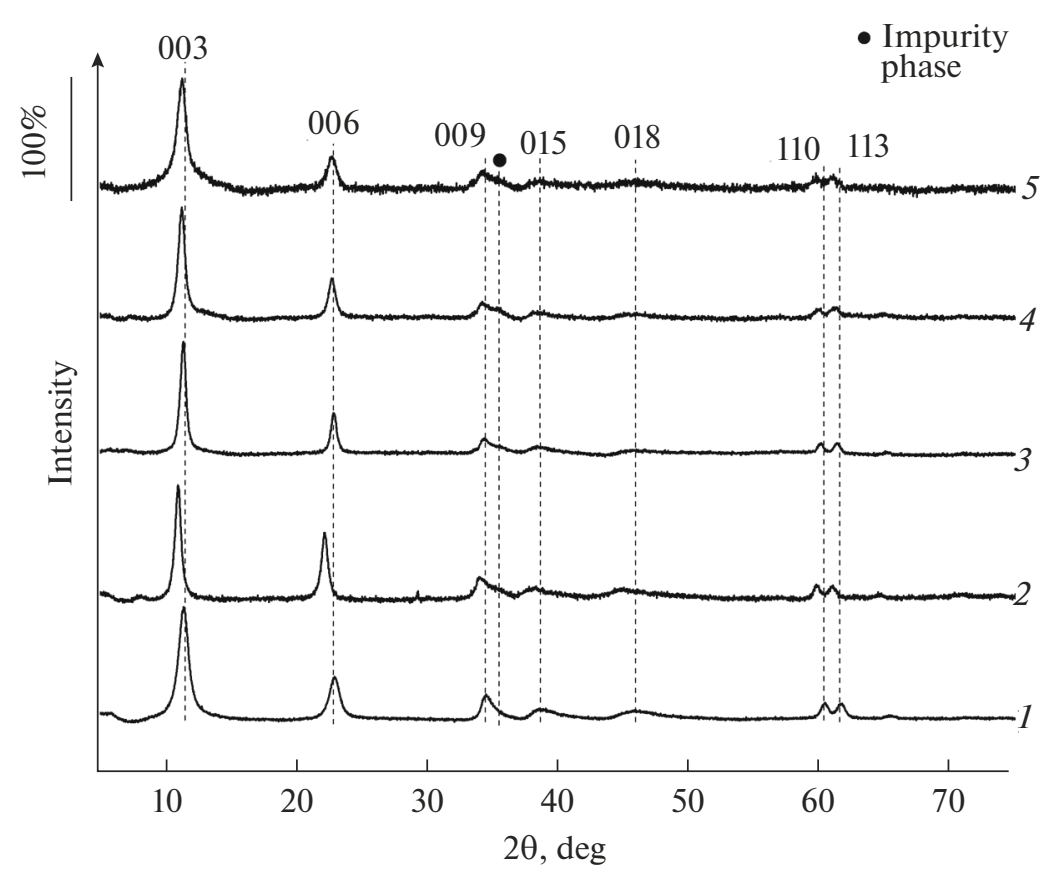

Fig. 5. X-ray powder diffraction patterns of the samples prepared by microwave synthesis: (1) $\mathrm{MgCo} 10 / \mathrm{AlFe} 10$, (2) $\mathrm{MgCo} 20 / \mathrm{AlFe} 20$, (3) MgCo30/AlFe30, (4) MgCo40/AlFe40, (5) MgCo50/AlFe50.

the material. Indeed, the reflections from the impurity phase are weaker in the X-ray diffraction patterns of the samples prepared by microwave synthesis, and the sample obtained by this method and containing little iron and cobalt is not attracted by the magnet.
The nature of the phase responsible for the magnetic properties of the samples remains open to question. Comparison of the X-ray diffraction patterns of the synthesized samples with reference data leads us to assume that the impurity phase is $\mathrm{CoFe}_{2} \mathrm{O}_{4}(\mathrm{PDF} 2$ no. 

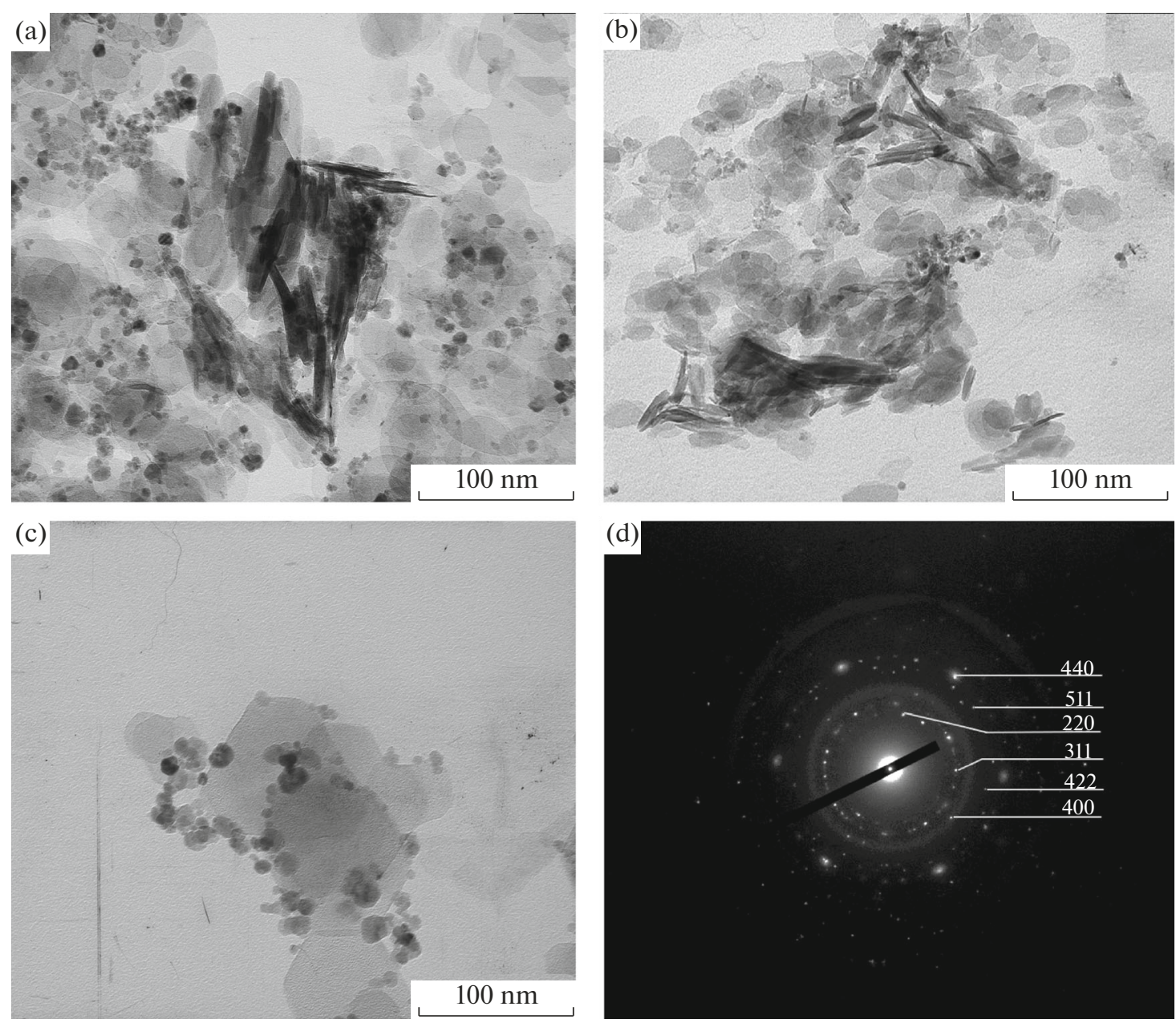

Fig. 6. TEM images of the samples prepared by different techniques: (a) MgCo40/AlFe40-c, (b) MgCo40/AlFe40-mw, and (c) $\mathrm{MgCo} 40 / \mathrm{AlFe} 40-\mathrm{ht}$; (d) selected area electron diffraction pattern of particles of the impurity phase $\left(\mathrm{CoFe}_{2} \mathrm{O}_{4}\right)$.

00-001-1121). The spinel structure, with the 111, 220, 311 , and 511 reflections, was identified with certainty in the X-ray diffraction patterns of the samples prepared via coprecipitation. The formation of a spinel phase is also evidenced by the fact that trimetallic LDHs containing only iron or only cobalt have no magnetic properties.

Spinel $\mathrm{CoFe}_{2} \mathrm{O}_{4}$ is known to exhibit ferromagnetic behavior at room temperature [18]. The formation of such structures is possible under the synthesis conditions of this study. In particular, according to Roy et al. [19] $\mathrm{CoFe}_{2} \mathrm{O}_{4}$ can be formed in the case of coprecipitation with a sodium hydroxide solution from aqueous solutions of $\mathrm{Co}(\mathrm{II})$ and $\mathrm{Fe}$ (III) chlorides in the molar ratio $1: 2$ at $80^{\circ} \mathrm{C}$. Liu et al. [18] described the hydrothermal synthesis of spinel $\mathrm{CoFe}_{2} \mathrm{O}_{4}$ nanoparticles at different temperatures from 90 to $180^{\circ} \mathrm{C}$ with the use of cobalt(II) acetate and iron(III) chloride as sources of metal cations and potassium hydroxide as a precipitant.
The morphology of the samples synthesized in this study was examined by TEM. The samples prepared by all three methods were observed to contain aggregates of platelike particles, including those hexagonal in shape, characteristic of LDHs (Fig. 6). Along with them, crystals with another shape were observed. Figure $6 \mathrm{~d}$ shows a selected area electron diffraction pattern of the impurity phase in the MgCo40/AlFe40-ht sample. The observed diffraction rings can be indexed as $220,311,400,422,511$, and 440 , which corresponds to the face-centered cubic spinel lattice and agrees with the X-ray diffraction data. Most likely, precipitation with a mixture of sodium hydroxide and sodium carbonate in our previous studies [10] is less favorable for the formation of the spinel phase because of the precipitation of basic iron and cobalt carbonates. The use of a carbonate-free reaction system in this study resulted in the formation of a magnetic phase at lower iron and cobalt concentrations.

INORGANIC MATERIALS Vol. $56 \quad$ No. 72020 


\section{CONCLUSIONS}

Materials containing $\mathrm{MgCo} / \mathrm{AlFe} \mathrm{LDHs}$ can be prepared not only via coprecipitation but also by hydrothermal treatment and microwave synthesis. If sodium hydroxide is used as a precipitant, the samples acquire magnetic properties at lower iron and cobalt concentrations than in the case of the hydroxide-carbonate precipitation process. The magnetic properties of the synthesized materials are probably due to the presence of spinel $\mathrm{CoFe}_{2} \mathrm{O}_{4}$ as an impurity phase. At identical reaction mixture compositions, microwave synthesis yields a smaller amount of the spinel phase. All three synthesis methods yield a well-crystallized LDH phase in nitrate form.

\section{FUNDING}

This work was supported by the Russian Foundation for Basic Research, grant no. 18-29-2103 mk.

\section{ACKNOWLEDGMENTS}

We are grateful to our colleagues at the Technologies and Materials Shared Research Facilities Center, Belgorod National Research University.

\section{REFERENCES}

1. Cavani, F., Trifirò, F., and Vaccari, A., Hydrotalcitetype anionic clays: preparation, properties and applications, Catal. Today, 1991, vol. 11, pp. 173-301. https://doi.org/10.1016/0920-5861(91)80068-K

2. Tret'yakov, Yu.D., Eliseev, A.A., and Lukashin, A.V., Synthesis of functional nanocomposites based on solidphase nanoreactors, Russ. Chem. Rev., 2004, vol. 73, no. 9, pp. 974-998. https://doi.org/10.1070/RC2004v073n09ABEH000918

3. Rives, V., Arco, M., and Martín, C., Intercalation of drugs in layered double hydroxides and their controlled release: a review, Appl. Clay Sci., 2014, vol. 88-89, pp. 239-269.

https://doi.org/10.1016/j.clay.2013.12.002

4. Liang, X., Zang, Y., Xu, Y., Tan, X., Hou, W., Wang, L., and Sun, Y., Sorption of metal cations on layered double hydroxides, Colloids Surf., A, 2013, vol. 433, pp. $122-131$.

https://doi.org/10.1016/j.colsurfa.2013.05.006

5. Goha, K.-H., Lima, T.-T., and Dong, Z., Application of layered double hydroxides for removal of oxyanions: a review, Water Res., 2008, vol. 42, pp. 1343-1368. https://doi.org/10.1016/j.watres.2007.10.043

6. Wang, W., Zhang, N., Shi, Z., Ye, Z., Gao, Q., Zhi, M., and Hong, Z., Preparation of Ni-Al layered double hydroxide hollow microspheres for supercapacitor electrode, Chem. Eng. J., 2018, vol. 338, pp. 55-61. https://doi.org/10.1016/j.cej.2018.01.024

7. Fan, G., Li, F., Evans, D.G., and Duan, X., Catalytic applications of layered double hydroxides: recent advances and perspectives, Chem. Soc. Rev., 2014, vol. 43, pp. 7040-7066.

https://doi.org/10.1039/C4CS00160E
8. Tanasoi, S., Mitran, G., Tanchoux, N., Cacciaguerra, T., Fajula, F., Sandulescu, I., Tichit, D., and Marcua, I.-C., Transition metal-containing mixed oxides catalysts derived from $\mathrm{LDH}$ precursors for short-chain hydrocarbons oxidation, Appl. Catal., A, 2011, vol. 395, pp. 78-86. https://doi.org/10.1016/j.apcata.2011.01.028

9. Li, Q., Xing, L., Lu, X., Li, N., and Mingxiang, X., Magnetic properties of $\mathrm{Mg} / \mathrm{Co}(\mathrm{II})-\mathrm{Al} / \mathrm{Fe}(\mathrm{III})$ layered double hydroxides, Inorg. Chem. Commun., 2015, vol. 52 , pp. $46-49$.

https://doi.org/10.1016/j.inoche.2014.12.014

10. Ryl'tsova, I.G., Nestroinaya, O.V., Lebedeva, O.E., Vorontsova, O.A., Kosova, N.I., and Kurzina, I.A., New magnesium cobalt iron double hydroxides with hydrotalcite structure: synthesis and characterization, Russ. J. Inorg. Chem., 2014, vol. 59, no. 12, pp. 1652-1659. https://doi.org/10.1134/S0036023614120213

11. Ryl'tsova, I.G., Tarasenko, E.A., Nestroinaya, O.V., and Lebedeva, O.E., Sorption properties of $\mathrm{MgCo} / \mathrm{AlFe}$ layered double hydroxides, Sorbtsi. Khromatogr. Protsessy, 2019, vol. 19, no. 3, pp. 305-314. https://doi.org/10.17308/sorpchrom.2019.19/747

12. Xu, Z.P. and Zeng, H.C., Decomposition pathways of hydrotalcite-like compounds $\mathrm{Mg}_{1-x} \mathrm{Al}_{x}(\mathrm{OH})_{2}\left(\mathrm{NO}_{3}\right)_{x}$. $n \mathrm{H}_{2} \mathrm{O}$ as a continuous function of nitrate anions, Chem. Mater., 2001, vol. 13, no. 12, pp. 4564-4572. https://doi.org/10.1021/cm010347g

13. Seftel, E.M., Popovici, E., Mertens, M., Cool, P., and Vansant, E.F., Infrared and Raman spectroscopic study of Sn-containing $\mathrm{Zn} / \mathrm{Al}$-layered double hydroxides, $J$. Optoelectron. Adv. Mater., 2008, vol. 10, pp. 3477-3481.

14. Kloprogge, J.T., Wharton, D., Hickey, L., and Frost, R.L., Infrared and Raman study of interlayer anions $\mathrm{CO}_{3}^{2-}$, $\mathrm{NO}_{3}^{-}, \mathrm{SO}_{4}^{2-}$ and $\mathrm{CIO}_{4}^{-}$in $\mathrm{Mg} / \mathrm{Al}$-hydrotalcite, $\mathrm{Am}$. Mineral., 2002, vol. 87, pp. 623-629. https://doi.org/10.2138/am-2002-5-604

15. Evans, D.G. and Slade, R.C.T., Structural aspects of layered double hydroxides, Layered Double Hydroxides, Duan, X. and Evans, D.G., Eds., Structure and Bonding, vol. 119, Berlin: Springer, 2005, pp. 1-87. https://doi.org/10.1007/430_005

16. Rozov, K.B., Berner, U., Kulik, D.A., and Diamond, L.W., Solubility and thermodynamic properties of carbonatebearing hydrotalcite-pyroaurite solid solutions with a $3: 1 \mathrm{Mg} /(\mathrm{Al}+\mathrm{Fe})$ mole ratio, Clays Clay Miner., 2011, vol. 59 , no. 3 , pp. $215-232$.

https://doi.org/10.1346/CCMN.2011.0590301

17. Abellen, G., Carrasco, J., and Coronado, E., Room temperature magnetism in layered double hydroxides due to magnetic nanoparticles, Inorg. Chem., 2013, vol. 52 , no. 14 , pp. $7828-7830$. https://doi.org/10.1021/ic400883k

18. Liu, W., Chan, Y., Cai, J., Leung, C., Mak, C., Wong, K., Zhang, F., Wu, X., and Qi, X.D., Understanding the formation of ultrafine spinel $\mathrm{CoFe}_{2} \mathrm{O}_{4}$ nanoplatelets and their magnetic properties, J. Appl. Phys., 2012, vol. 112, paper 104306 .

https://doi.org/10.1063/1.4765033

19. Roy, P., Manjura, H.S., Liba, S.I., and Choudhury, S., Investigation of various magnetic features of spinel type cobalt ferrite $\left(\mathrm{CoFe}_{2} \mathrm{O}_{4}\right)$ nanoparticles tuned by annealing temperature, AIP Adv., 2018, vol. 8, paper 105124. https://doi.org/10.1063/1.5040890

Translated by $O$. Tsarev 